\title{
Early childhood caries experience of children accessing selected immunization facilities in Johannesburg.
}

\begin{abstract}
Introduction: Despite notable achievements in the enhancement of the oral health of populations globally, early childhood caries (ECC) remains a common condition, particularly in developing countries. Mother and child oral health programs at immunization facilities were piloted in two Gauteng Districts in 2015 in order to address the burden of disease. Hence there was an opportunity to assess the ECC experience and risk factors contributing to ECC at these sites.
\end{abstract}

Methods: This retrospective study included records of mother and child pairs who attended the Diepsloot and Vanderbijlpark clinics Mother and Child programs in 2015. The ages of the children ranged between six months and six years. Data were collected from the oral health assessments and questionnaires used in the program.

Results: Differences in the distal and proximal factors at the two sites were identified from the 446 records assessed. Children in Diepsloot had significantly higher levels of mean $\mathrm{dmft}$ at $0.43(1.26)$ than those in Vanderbiljpark $0.22(0.70)$, $p=0.01$.

Conclusion: Though the general caries experience in this population was low (13.6\%), program planners still need to consider differences in oral health exposures and hygiene practices in order to implement activities that are appropriate to the communities being served.

Key Words: Early Childhood Caries; Proximal Risk Factors; Distal Risk Factors; Mother and child oral health program

\section{INTRODUCTION \& BACKGROUND}

Despite notable achievements in the enhancement of the oral health of populations globally, Early Childhood Caries

1. Dr Mpho Matlakale Molete: BDS, MSC, MDent Wits) Community Dentistry, School of Oral Health Sciences, Faculty of Health Sciences University of the Witwatersrand, Johannesburg.

2. Ms. Neliswa Patience Phakela: $\mathrm{Dip} O H: B O H ; M S C D P H$. Community Dentistry, School of Oral Health Sciences, Faculty of Health Sciences University of the Witwatersrand, Johannesburg.

\section{Corresponding author}

Dr Mpho Primrose Molete:

Community Dentistry, School of Oral Health Sciences, Faculty of Health Sciences, University of the Witwatersrand, Yale Road, Parktown, 2193.

Tel: 064752 3860, E-mail: Mpho.molete@wits.ac.za

\section{ACRONYMS}

ECC: early childhood caries

(ECC) remains a common dental condition. ${ }^{1}$ In developing countries the prevalence of the condition is approximately $60 \% .^{2}$ Once dental caries occurs, the effects persist throughout life, even after the lesion is treated. ${ }^{3}$ Pain and suffering due to untreated tooth and gum disease can lead to problems in speaking, eating, and learning. When the primary teeth are lost early, the surrounding teeth may drift into the empty space, and lead to malocclusion of the permanent teeth in the future. ${ }^{4}$ In addition, Early Childhood Caries (ECC) is a predictor of future adult caries. ${ }^{5}$ Treatment of the condition is costly in both the short and long term. Costs which may be incurred range from treatment under general anaesthesia to complex restorative and orthodontic care. ${ }^{6}$

The causes of ECC are not confined to the biological mechanism but involve socio-behavioural factors which have been commonly observed among children from low socio- economic backgrounds. ${ }^{7.8}$ Although children from economically disadvantaged backgrounds are at risk of ECC, they are not all affected the same way as there are other socio-behavioural risk and protective factors at play. ${ }^{7}$

According to the National Children's Oral Health Survey undertaken in South Africa in 2004, dental caries amongst children was found to be more pronounced in the primary teeth. There was a $50.5 \%$ prevalence amongst $4-5$ year olds, rising to $60.3 \%$ amongst 6 year olds. ${ }^{9}$ Furthermore, over $90 \%$ of these children went untreated for caries, reflecting on the inability of the country to address the caries burden. ${ }^{9}$

One of the attempts made by the South African Department of Health at addressing the challenge of ECC was by including oral health examinations in the Road to Health immunization programme for children. Mother and Child oral health programmes were then proposed at various immunization sites at District Primary Health Care facilities. There are currently two pilot sites operating in Johannesburg, one is in Diepsloot and the other in Vanderbijlpark. The Oral Hygienists at the facilities conduct oral health assessments on the children and provide tailored oral health advice to individual mothers. 
The oral health examinations are conducted at five initial immunization visits and the mother and child pairs are provided with oral health care and diet advice and sent home with a free toothbrush, fluoridated toothpaste and an educational pack.

Diepsloot is based in a densely populated township in the Northern part of Johannesburg. It is an informal settlement where many of the people live in shacks that are $3 \mathrm{~m}$ by $2 \mathrm{~m}$ in size, and are assembled from scrap metal, wood, plastic and cardboard. There is a high unemployment rate (40-50\%) and some families lack access to basic services such as piped water in their homes, sewage and rubbish removal. ${ }^{10,11}$ There are two Primary Health Care clinics and there is a mobile dental facility located at one of the facilities.

Vanderbijlpark on the other hand is a town situated in Sedibeng which is a district located in the Southern part of Johannesburg. Its infra-structure is better developed than that of Diepsloot; $95.5 \%$ of the population have access to piped water and $91.2 \%$ have access to sanitation. This industrial town experiences approximately 35\%-40\% unemployment, ${ }^{12}$ and there are three Primary Care Dental Facilities located in the area.

\section{Conceptual Framework}

According to the $\mathrm{WHO}$, Risk is defined as the probability of an adverse outcome, which does not occur in isolation and often stems from complex chains that occur over time..$^{13,14}$ The chain of events leading to an adverse health outcome may be either proximal or distal. The proximal factors come close to directly causing the disease and the distal factors occur further back in the chain and are shaped by broader social determinants of health. ${ }^{13}$ Distal factors include oral health services, socio-cultural risk factors and environmental factors. Proximal factors include use of oral health services, oral hygiene practices, dietary habits, excessive alcohol and tobacco use. Outcomes include oral health status, impairment of function and quality of life (Figure 1). ${ }^{14}$

\begin{tabular}{|c|c|c|}
\hline Distal factors & Proximal facto & Outcomes \\
\hline \multirow[t]{2}{*}{$\begin{array}{l}\text { Health system \& } \\
\text { oral health }\end{array}$} & $\begin{array}{l}\text { Use of oral } \\
\text { health services }\end{array}$ & Outcome \\
\hline & & Oral health status \\
\hline \multirow{2}{*}{$\begin{array}{l}\text { Socio cultural } \\
\text { risk factors }\end{array}$} & Plisk behaviour & Impairment \\
\hline & & Quality of life \\
\hline \multirow{3}{*}{$\begin{array}{l}\text { Environmental } \\
\text { risk factors }\end{array}$} & Diet & Systemic health \\
\hline & Tobacco & \\
\hline & Alcohol & \\
\hline
\end{tabular}

Figure 1: The socio-behavioural risk factor approach as suggested by $\mathrm{WHO}$ (Petersen, 2005)

At the time of the study, the pilot sites had been operational for over a year and had not been evaluated. Therefore the study aimed to assess the caries experience and to evaluate the risk factors associated with the condition at these sites.

\section{METHODS}

This was a retrospective study which included records of mother and child pairs who attended the Diepsloot and
Vanderbijlpark Mother and Child oral health programs in 2015. A technique of convenience sampling was applied in which all records of children between the ages of six months and six years were requested. Records that had missing data, and those of children that were outside the age range were excluded from the study. A sample of 446 records (223 from each site) was obtained which satisfied the requirements for the sample size as statistically determined for a 95\% confidence interval (Epi-info version 3.5.4).

The data items which were recorded were selected after considering the variables from an adapted WHO framework. The variables specifically included in the study were oral health care availability; education; oral hygiene practices; sugar consumption and oral health status (Figure 2). The data were collected from programme records by a dentist and an oral hygienist who were calibrated in order to reduce intra- and inter- examiner variability (WHO, 2013).

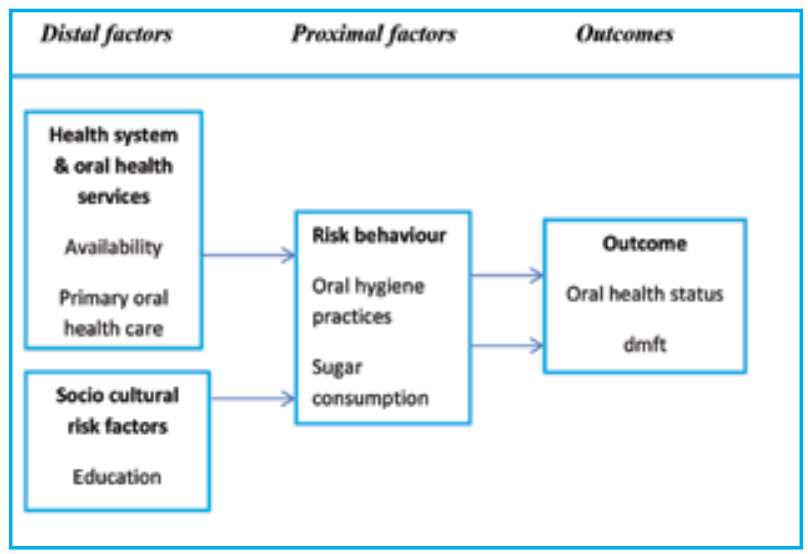

Figure 2: Variables adapted from the socio-behavioural risk factor approach.

The questionnaires used in the program had been adapted from those used by the Texas Department of State Health Services in 2015. These questionnaires were in English and they had been utilised by the examining oral hygienist and dentist as they were interviewing and advising the mothers. The form embraced socio-cultural and behavioural questions that included the following: demographic information of the mother and the child; health history; dental history; diet and nutrition and oral hygiene information.

Information on the socio-behavioural risk factors was also collected from the questionnaires. Clinical data was determined from the decayed, missing, filled teeth index (dmft) component which was contained in the children's Road to Health immunization booklet.

Data Collection and management

The data were captured onto Excel and then imported to STATA (version 7) for analysis. Each mother to child pair record was accorded an identity number which was the same for the clinical examination and the questionnaire. This ensured that the data from the clinical exam and the questionnaire were matched.

\section{STATISTICAL METHODS}

Descriptive statistics were utilised to analyse demographic variables, distal risk factors; proximal risk factors and the $\mathrm{dmft}$. Numerical variables were analysed by using means and standard deviation. Caries prevalence rate and $\mathrm{dmft}$ 
scores were calculated. The caries prevalence and odds ratios were additionally calculated. The $t$-test was used to assess any differences in the mean $\mathrm{dmft}$ scores. Bivariate analysis was undertaken to determine associations between the risk factors and the sites. Statistical significance was set at $p<0.05$.

\section{RESULTS}

Demographic characteristics

Half of the children (52.91\%) whose records $(n=446)$ were examined had been between the ages of 6-23 months. Caregivers were largely unemployed (69.28\%). Vanderbiljpark had more than one Oral Health facility within a $5 \mathrm{~km}$ radius of the immunization site. Diepsloot had only one facility, which was a mobile dental unit (Table 1).

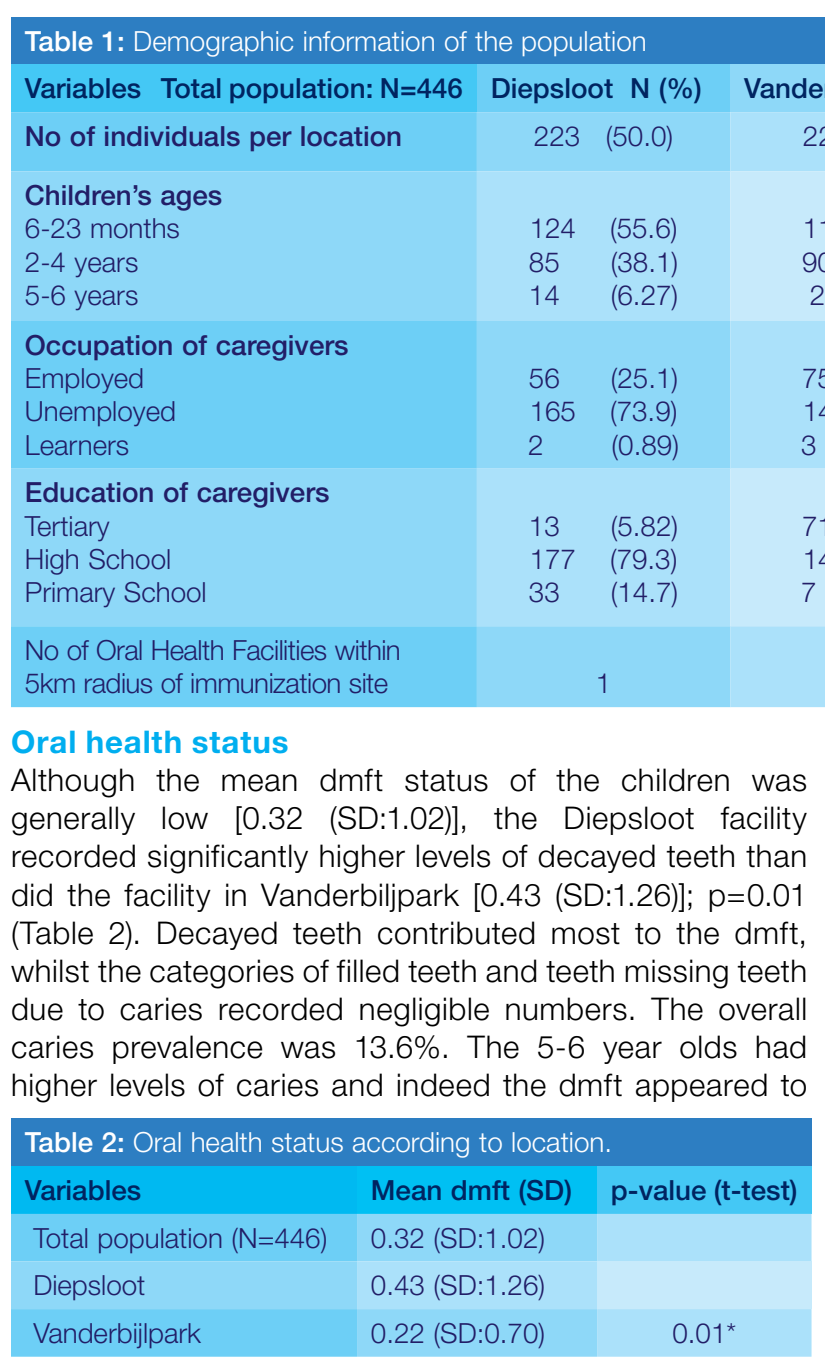

\begin{tabular}{|c|c|c|}
\hline Variables & Mean dmft (SD) & $\begin{array}{l}\text { p-value } \\
\text { (pearson's chi sq) }\end{array}$ \\
\hline 6-23months & 0.084 (SD:0.56) & \\
\hline 2-4 years & 0.48 (SD:1.08) & \\
\hline 5-6 years & 2.4 (SD: 1.63) & $<0.001^{*}$ \\
\hline
\end{tabular}

increase with age (Table 3.)

Risk Factors

Feeding patterns of the children at the two sites were found to be different. These were in terms of bottle feeding
Table 4: Feeding patterns \& oral hygiene habits

\begin{tabular}{|l|c|c|c|}
\hline Variables & $\begin{array}{c}\text { Frequencies } \\
(\mathbf{n})\end{array}$ & $\begin{array}{c}\text { Propotions } \\
(\%)\end{array}$ & $\begin{array}{c}\text { p-values } \\
\text { (pearson's chi sq) }\end{array}$ \\
\hline Breastfed & 323 & 72.42 & \\
\hline Diepsloot & 160 & 49.53 & 0.58 \\
\hline Vanderbijlpark & 163 & 50.46 & \\
\hline Bottlefed & 173 & 43.14 & \\
\hline Diepsloot & 71 & 41.04 & $<0.001^{*}$ \\
\hline Vanderbijpark & 102 & 58.95 & \\
\hline Sugar in porridge / tea & 280 & 62.78 & \\
Diepsloot & 103 & 36.78 & \\
\hline Vanderbijlpark & 177 & 63.21 & $<0.001^{*}$ \\
\hline Cleaning of gums \& & 278 & 62.33 & \\
teeth & & & \\
Diepsloot & 113 & 40.64 & $<0.001^{*}$ \\
Vanderbiljpark & 165 & 59.35 & \\
\hline
\end{tabular}

and the intake of sugar in tea or porridge. Children in Vanderbiljpark were more likely to be bottle fed and were exposed to sugar to a greater extent than those in Diepsloot (Table 4).

Differences in oral hygiene practices were also identified, although in general a large number of caregivers (62.33\%) reported to be cleaning their children's mouths, particularly amongst those from Vanderbijlpark (59.39\%), whereas most in Diepsloot $(65.47 \%)$ reported not to have performed this practice (Table 4).

The bivariate analysis indicated that the 2-6 year old children were twice as likely to suffer from dental caries than the 6-23 month olds [OR 2.07; Cl:1.77-2.43 $(p<0.001)]$. Significant differences between the means of the children's data at the two sites are shown on Figure 3.

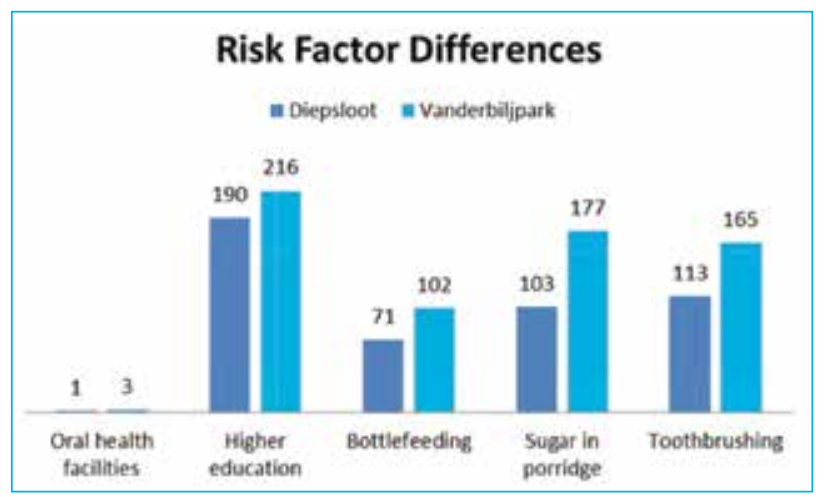

Figure 3: Risk factors associated with dental caries at the two sites.

\section{DISCUSSION}

Diepsloot and Vanderbiljpark have similar socioeconomic standings as was reflected in their general high unemployment rate (40-50\%). ${ }^{10,12}$ Furthermore the results indicated that a majority of the mothers in the population were unemployed (69\%). Despite these similarities, the oral health status of the children was found to be significantly different and moreover, there were differences in parental educational exposure and in accessing oral health care. The differences contributing to ECC were largely due to the mother's educational levels, the behavioral patterns of feeding and of oral hygiene practices, as indeed is consistent with the literature. ${ }^{7,14}$ 
The Diepsloot data indicated higher levels of dmft (0.43: SD: 1.26) which were accompanied by poor oral hygiene, low caregiver education and limited access to oral health care. These findings are consistent with some of those reported by Petersen et al (2005). In that paper the authors outline the global burden of disease and describe the sociobehavioral risk factors associated with the condition. They found, from a review of studies assessed, that prevailing risk factors in developing countries included the level of education of the parents, the location/urbanisation, ethnic group, tooth brushing habits and number of dental visits. ${ }^{14}$

Although the dmft was lower for children in Vanderbiljpark (0.22: SD:0.70), the feeding habits of sugar consumption and prolonged bottle feeding were high. A protective effect may be attributed to the fact that $59 \%$ of the mothers reported cleaning their children's teeth, which was found by a systematic review to have been an important parameter in the prevention of dental caries in children. ${ }^{14}$ Furthermore this community had more access to dental services, in contrast to the single mobile dental service in Diepsloot.

In the current study, the caries prevalence was shown to proportionally increase with increasing age. This could be attributed to the fact that as more teeth continue to erupt between the ages of six months and six years of age, there is an increased exposure of the teeth to sugar as children grow up, leading to dental caries. ${ }^{3}$ The study further demonstrates that both distal and proximal risk factors are at play in the development of ECC. ${ }^{3}$ Contextual sociobehavioural factors that emerged in this particular population included, specifically, the differences in accessibility to oral health facilities, the mother's educational levels, oral hygiene practices and in sugar consumption.

According to the literature, the barriers to oral health care access among pre-school children are multifaceted. They not only are associated with a lack of oral health facilities, but also include a lack of awareness among the parents, the dental professionals and primary health care nursing staff in providing the appropriate preventative care. ${ }^{15-17}$ According to a study conducted in Tshwane which assessed integration of oral health within maternal and child health services, $38 \%$ of the caregivers with poor educational backgrounds did not value the importance of the primary dentition ${ }^{18}$ and hence did not take their children to oral health facilities in the first few years of life. Moreover, primary health care immunisation clinics were found not to give priority to oral health as the nurses were overburdened and lacked sufficient oral health knowledge. ${ }^{15,17}$ Dental professionals in general practice have also been shown not to perceive themselves as having a primary role in the prevention of oral disease of pre-school children. ${ }^{16}$

Bhardwaj \& Bhardwaj (2014) suggested that a high educational background in a mother was associated with a positive dental attitude and knowledge. ${ }^{17}$ This was the case in our study, as the mothers in Vanderbiljpark had better levels of education than those in Diepsloot; therefore, as seen in the results, brushing practices were implemented early on in the lives of their children. A similar study of child-caregiver pairs of children between the ages of 6-36 months in Uganda reported that caregivers who were exposed to oral health education had children that were less likely to suffer from ECC [OR:0.3 (0.09-0.93)]..$^{19}$ In South
Africa, half (55\%) of the caregivers in a peri-urban setting reported that they received their oral health education largely from the media, which may not necessarily be reliable. ${ }^{18}$ This demonstrated that there were large gaps in the dissemination of appropriate oral health information to care-givers of low socio-economic standing.

It is undisputed that oral hygiene and diet play a major role in ECC. ${ }^{13,15,20}$ Furthermore, an early start of tooth brushing with toothpaste impacted positively on oral health while a high consumption of sugary foods and beverages impacted negatively. ${ }^{21,22}$ One of the studies that was carried out at kindergartens in Germany demonstrated that children who started brushing in their first year of life had a lower dmft increment (0.65) than those who brushed after their first year of life (1.14), $p=0.001$. Those with a high sugar intake had a higher (0.85) dmft increment than those with a low sugar intake $(0.65) p=0.02 .{ }^{23}$

In terms of implications for the ongoing pilot programs, this study demonstrated how the programs can be strengthened by addressing contextual factors affecting the oral health outcomes of the children. This is found to be of influence in contributing to ECC, such factors included social, cultural, economic aspects and access to care. ${ }^{24}$ Literature suggests that the factors mentioned not only influenced how the program was implemented, but also impacted on the oral health outcomes resulting from the program. ${ }^{24.25}$ Therefore one of the ways of mitigating against a rise in the incidence of caries is to implement oral health promotion programs when children are in their pre-primary years and additionally to bear in mind unique contextual factors which may be at play at the sites. ${ }^{24,25}$ This may assist the country in eventually achieving the Gauteng Oral Health goal of achieving $60 \%$ or more caries free six year old children. ${ }^{26}$

\section{LIMITATIONS}

The study could not provide information on environmental influences as the secondary data used had not provided that sort of information. There was also missing data on the ages of the mothers and therefore an analysis could not be undertaken to consider any association between mother age and oral health status. Given that this was a cross-sectional study no causality could be drawn, however the results obtained provide useful information for strengthening the mother and child programs.

\section{CONCLUSION AND RECOMMENDATIONS}

The study demonstrated that the ECC experience and the risk factors linked to the condition at the two immunization facilities varied and that the condition increased with age among children between six months and six years old. In addition, distal and proximal contextual risk factors need to be considered in planning programs that are appropriate to the population being served.

\section{Acknowledgments}

The authors would like to thank Dr Maphefo Thekiso and Ms Nothemba Zitho for their contributions to the study.

\section{References}

1. Naidoo S, Myburgh N. Nutrition, oral health and the young child. Maternal and Child Nutrition 2007; 3: 312-21.

2. Bourgeois DM, Llodra JC. Global burden of dental condition among children in nine countries participating in an 
international oral health promotion programme, 2012-2013. International Dental Journal 2014; 64(s2):27-34.

3. Sarumathi T, Saravan KB, Manjula D et al. Prevalence, severity and associated factors of dental caries in 3-6 year old children. J.Clin Diagn Res. 2013;7 (8):1789-92.

4. Congiu G, Campus G, Luglie PF. Early Childhood Caries prevalence and background factors: A review. Oral Health Prev Dent.2014;1: 71-6.

5. American Academy of Paediatric Dentistry. Policy on Early Childhood Caries (ECC): Classifications, Consequences, Preventive Strategies. Oral Health Policies Reference Manual; (2014);36:(6)50-52.

6. Sen B, Blackburn J, Morrisey MA, Kilgore ML, Becker DJ, Caldwell C, Menachemi N. Effectiveness of preventive dental visits in reducing nonpreventive dental visits and expenditures. Pediatrics 2013;131(6):1107-13.

7. Finlayson TL, Siefert K, Ismail Al, Sohn W. Psychosocial factors and early childhood caries among low-income AfricanAmerican children in Detroit. Community Dent Oral Epidemiol. 2007; 35:439-48

8. Postma TC, Ayo-Yusuf OA, Wyk PJ. Socio-demographic correlates of early childhood caries prevalence and severity in a developing country-South Africa. International Dental Journal 2008;58(2):91-7.

9. Wyk PJ, Wyk C. Oral health in South Africa. International Dental Journal 2004;54(S6):373-7.

10. Ngwenya P, Zikhali P. Income and expenditure patterns in Diepsloot. Economics of South African Townships. 2014 Aug 22:219.

11. S4.brown.edu An overview of Diepsloot. (2014). Available in: www.s4.brown.edu/southafrica/Reports/Johannesburg/ Diepsloot.pdf. (Accessed on 17/06/15).

12. Sedibeng Municipality. Sedibeng District Municipality- Annual Report 2010-11(2011). Available in: http://www.sedibeng.gov. za/a keydocs/ar_2010_11/ar. (Accessed on 17/06/15).

13. WHO. The World Health Report 2002. Reducing risks, promoting health life. (2002) Geneva: WHO.

14. Petersen PE, Bourgeois D, Ogawa H, Estupinan-Day S, Ndiaye C. The global burden of oral diseases and risks to oral health. Bulletin of the World Health Organization 2005 ;83(9):661-9.

15. Harris R, Nicoll AD, Adair PM, Pine CM. Risk factors for dental caries in young children: a systematic review of the literature. Community Dental Health 2004 ;21(1):71-85.

16. Gussy MG, Waters E, KilpatrickNM. A qualitative study exploring barriers to a model of shared care for pre-school children's oral health. British Dental Journal 2006;201(3):165-70.

17. Bhardwaj SV, Bhardwaj A. Early childhood caries and its correlation with maternal education level and socio-economic status. Journal of Orofacial Sciences 20141;6(1):53.

18. Kolisa Y. Assessment of oral health promotion services offered as part of maternal and child health services in the Tshwane Health District, Pretoria, South Africa. African Journal of Primary Health Care \& Family Medicine 2016;8(1):1-8.

19. Masumo R, Bardsen A, Mashoko K, Astron AN. Prevalence and socio-behavioural influence of early childhood caries and feeding habits among 6-36 months old in children in Uganda and Tanzania. BMC Oral Health 2012;12 (24):1-13.

20. Mahomed N, Barnes J. Characteristics of children under 6 years of age treated for Early Childhood Caries at Tygerberg Oral Health Centre, South Africa. Journal of Clinical Paediatric Dentistry 200; 32 (3):247-52.

21. Marcenes W, Kassebaum NJ, Bernabé E, Flaxman A, Naghavi M, Lopez A, Murray CJ. Global burden of oral conditions in 1990-2010: a systematic analysis. Journal of Dental Research 2013;92(7):592-7.

22. Sohn W, Burt BA, Sowers MR. Carbonated soft drinks and dental caries in the primary dentition. Journal of Dental Research 2006;85(3):262-6.

23. Winter J, Glaser M, Heinzel-Gutenbrunner M, Pieper $K$. Association of caries increment in preschool children with nutritional and preventive variables. Clinical Oral Investigations 2015;19(8):1913.

24. Peters DH, Adam T, Alonge O, Agyepong IA, Tran N. Implementation research: what it is and how to do it. BMJ. 2013;347:f6753.
25. Proctor E, Silmere H, Raghavan R, Hovmand P, Aarons G, Bunger A, Griffey R, Hensley M. Outcomes for implementation research: conceptual distinctions, measurement challenges, and research agenda. Administration and Policy in Mental Health and Mental Health Services Research 2011;38(2):65-76.

26. Carroll C, Patterson M, Wood S, Booth A, Rick J, Balain S. A conceptual framework for implementation fidelity. Implementation Science 2007;2:40.

27. Department of Health, (2010). Gauteng Oral Health Strategy: Report: Provincial Department of Health 2010:2-21. 